\title{
Socio-Cultural Factors Militating Against the Work Performance and Advancement of Female Executives in Nigerian Public Health Institutions.
}

\author{
Stephen Omokojie \\ IRUNE PhD, (JP) FCMI.*
}

\begin{abstract}
This study was undertaken to empirically examine the extent to which socio-cultural factors militate against the work performance and advancement of female executives in Nigerian Public Health Institutions. To this effect, a survey was carried out and the sampled population for the study consisted of male and female executives of health and health related Institutions in Benin City, Nigeria. Likert-type questionnaires were administered to 270 respondents, who were systematically and randomly selected and of which 185 were retrieved. The data collected were analyzed using descriptive inferential statistics. Research findings show that the work performance of female executives in the institutions surveyed are significantly affected negatively by a number of socio-cultural factors such as biological nature of women, women's role in children's upbringing, extension of cultural practices to workplace, and so forth. Further findings regarding the perception of the work performance of female executives across gender was however found to be insignificant. Given the foregoing findings, the researcher recommends the need for concerted efforts by all stakeholders dealing with gender issues to adopt deliberate and systematic gender mainstreaming involving multi-sectoral approach, while the government should demonstrate political will and financial commitment which will ensure the minimization of negative cultural factors militating against the work performance, advancement and upward mobility of female executives in the public health Institutions.
\end{abstract}

\section{Introduction}

Societies worldwide at different times and at different geographical locations have never been egalitarian. An egalitarian society where all men are equal and no one will experience the indignity of being relegated to a lowly position, which command little respect is non-existent and clearly, the egalitarian society remains a dream. All human societies from the simplest to the most complex have some forms of social inequalities because, power, prestige, social status, wealth and other resources are unequally distributed between individuals, groups, societies and countries worldwide.

Social inequalities refer to the existence of socially created inequalities (Haralambos et al, 1995). Social inequalities are accomplished by beliefs of dominance of certain groups in the society based on a number of factors that range from biology to spiritual. According to Wikipedia the free Encyclopedia, Social inequalities is a situation in which individual groups in a society do not have equal social status, social class and social circle. Areas of social inequality, it goes further, include voting rights, freedom of speech and assembly, the extent of property rights and access to education, healthcare, quality housing, travelling, transportation, vacationing and other social goods. Inequality is also manifested in the quality of the family and neighbourhood life, occupation, job satisfaction, access to credit, wealth, race and gender. Social inequalities further involve the belief that some individuals are socially defined as disadvantaged, underpriviledged, underachieved, nonimportant and inferior due to their life circumstances. One of the major social inequalities that has been sustained from time immemorial is gender inequality, which is the male domination of women in society. The practice of gender (male-female differentiation) results in structural deprivation of the female life and it is perpetuated by patriarchy, culture and glass ceiling effects and their impact as the sources of female domination are briefly examined as follows.

\section{Patriarchy}

Patriarchy is one of the major factors of female oppression worldwide. It is a social system in which the father or eldest male is the head of the household, having authority over women and children. Patriarchy also refers to a system of government by males and to the dominance of men in social and cultural systems and may also include title being traced through the male line (Webster's New World College Dictionary). Patriarchy manifests itself in the social, legal, political and economic organizations of a range of different cultures and has strong influence on modern civilization. Patriarchy is not just an issue of domination over women but also 
crucially means power exerted complexly by age as well as gender and by older men over women and children (Wikipedia the free Encyclopedia).

In Nigeria, it is generally recognized that the country is a patriarchal society and gender stereotypes pervade all social systems. Onyinye (2007) opined that in Nigeria as elsewhere religion and culture are instruments of women oppression. The patriarchal society sets the parameters for women structural unequal positions in families and markets by condoning gender-differential terms in inheritance rights and legal adulthood, by tacitly condoning domestic and sexual violence and sanctioning differential wages for equal or comparable work. Similarly the Nigerian Convention on the Elimination of all Forms of Discrimination Against Women (CEDAW) NGO Coalition Shadow Report (2008) noted that gender stereotypes continue to be reinforced in Nigeria as series of agents of socialization such as families, schools, churches, mosques and media have become the custodians as well as the disseminators of gender roles, stereotypes, prejudices and discriminatory culture. Girls and boys grow up in Nigerian society to accept males superiority over females and patriarchal structure have become unquestionable phenomenon.

\section{Christianity and Islam}

Christian and Islamic religions have been implicated in entrenching patriarchal attitude. Within the feminist theory, the Christians normally use the commands of God in Exodus 20:12 to justify the duties subordinates owe to superiors, 'Honour thy father' became an accepted norm for the duty to obey the king. This is further emphasized in Ephesians 5: 22, which gives injunction that wives should be submissive to their husbands. In this respect, Onyinye (2007) expresses the view that the Christian religion relegates women to the background, it preaches that women's role should be reproduction and domestic calls. It preaches women's subordination and gives women little role in the church. As for Islamic religion, Onyinye (2007) also states that Islamic religion laws give central place to paternalistic interpretation to women's appropriate roles and socialpolitical arrangement of the society and continues to place a lot of restriction on the rights of women. She asserts that in the traditional African religion, the woman exists as the pleasure of the man and that the Christian and Islamic religions are used by men as instrument to defend patriarchy. It is this religion; she noted is the basis of African culture and the basis of gender construction.

\section{Culture}

Culture is another instrument of male domination over female. The word culture is a concept which has many different inter-related meanings. To some people, the concept refers to excellence of taste or appreciation of fine arts, music, and humanities. Over the years, it has been the central focus of anthropological, sociological, socio-cultural studies and research and has been defined in various ways by different authors and writers on the subject. Hofstede (1994) for example defines culture as the collective programming of the mind that distinguishes the members of one human group from those of another. Culture in this sense is a system of collectively held values. In another dimension, a Nigerian Sociologist, Onwuejeogwu (1994), states that culture is all material objects made by man ranging from stone implement to atomic energy and all non-material things, thought out and institutionalized by man ranging from values, norms, to ideas like marriage, economy, politics, religion, music, drama, dance and language. The material and non-material forms according to him interact and interweave to form new complete forms.

Most sociologists believe that culture consist of learned behaviours of a given human society while some authors hold the view that men and women figure equally in cultural systems, however the power to participate in the process of negotiation has historically been divided along gender lines (Jekayinfa 1999, Jones 1969, Afonja 1996 and Onyinye 2007). Cultures vary widely with regards to the roles they assigned to different sexes. While one job may be regarded as a man's job in one society, it may be regarded as a woman's job in another. Child bearing is however, one constant factor that determines the division of labour in pre-industrial society. Culture is learned and shared, culture is transmitted from one generation to another and in this process, culture is modified, renewed or dropped and it is both static and dynamic (Jekayinfa 1999). Common trend discernable from the foregoing definitions show that cultures and traditions can be regarded as mechanisms for regulation, adjustment and control of our social actions manifested in religion, customs, habits, politics, legal, socio-economic organizations and other complex everyday social behaviours.

The Nigerian Convention on the Elimination of all forms of Discrimination Against Women (CEDAW) NGO Coalition Shadow Report (2008) observed that section 21(a) of Nigerian Constitution requires the State to protect, preserve and promote only Nigerian cultures that enhance human dignity and consistent with the fundamental objectives as provided in the chapter. The report however, noted that harmful traditional and cultural practices which discriminate against women still abound, and Nigeria still fall short of the desired result of giving males and females equal opportunities and equal access to opportunities to advance socially, economically and politically. Various discriminations exist in gender based division of labour, disparities between males and females, access to power and resources and gender bias in rights and entitlements. 
With regard to the cultural effects on male domination over female, Okome (2005), observes that the male dominant elements of Nigerian society remain strong. Many of these elements she argues, are located within the family where a woman is required to take care of her husband at home. Since most women also work outside their homes, this creates double burden and may limit the ability of women to devote an equal amount of attention and concentration on their careers or trade. In Nigeria law and administrative practice, the predominant attitude is that men are the household heads and have primary authority (Okome 2005). Alele - Williams, (1987) also attributed the discrimination against women in science and technology careers to cultural standards, values and practices, structural beliefs about gender roles and the production of knowledge. Onyinye (2007) asserts observed that women self advancement has been curtailed by the burden of reproduction particularly in Nigeria with a very high birth rate as well as the cultural roles associated with women as women take more time off work because of the burden of childcare and domestic affairs. CEDAW (2008) in their report observed also that gender stereotypes pervade the school system and curricular. Socialization in patriarchal cultures like Nigeria makes domestic chores and domestic affairs to be seen as the concern for women whilst men are associated with occupying public positions.

\section{Glass Ceiling}

Glass ceiling is another factor of female domination by male in both developed and developing countries. Glass ceiling is often used to describe invisible barriers (glass) through which women can see elite positions but cannot reach them (Davies-Netzley, 1998). The practice of glass ceiling worldwide prevent large numbers of women and ethnic minorities from obtaining and securing the most powerful positions in higher grossing jobs in workforce (Hesse-Biber, 2005), regardless of their qualifications and achievements. This practice lowers the chances of women from excelling in their chosen careers and prevents them from succeeding, developing and making full use of their potentials. This obviously is at a cost for the women as well as the society in terms of development.

This glass ceiling in various countries has been extended to household, particularly for women who feel they are being suppressed from going out to work. This barrier can make many women feel as if they are not worthy enough to have these high ranking positions, but also they feel as if their bosses do not take them seriously or actually see them as potential candidates (Nevil\& the US Department of Labor). In Nigeria, men mostly populate management positions of various organizations. Although, professional women in many organizations have increased tremendously and have made progress in the past three decades, the process has not been made easy by patriarchal, cultural and glass ceiling practices which have become formidable impediments to the advancement and work performance.

When we compare the status of men in positions of power, prestige and wealth today in Nigeria, women fall short and highly under-represented despite legislations/legal provisions and encouraging steps taken to include them in strategic position. This again obviously points to the existence of glass ceiling effects, interwoven with the problems of patriarchy and cultural practices at the top management levels and these prevent women and minorities from rising to the position of power and responsibility within Nigerian organizations. The glass ceiling continues to exist even when there are no explicit obstacles or legal constraints keeping women and minorities from acquiring advance jobs. The practice of glass ceiling in Nigeria takes various forms. In some organizations such as the Nigerian Police Force, the law specifically requires that women are to be unmarried at the time of enlistment in the Force. Similarly, the banks prefer single girls to married women with regard to employment. Some women and some girls are often exposed to sexual harassment in the process of recruitment and selection in workplaces in both public and private institutions. Furthermore, some women and girls in employment are similarly exposed to sexual harassment in the process of promotion. In the banks, females are often exposed to external sexual harassment as they are given unrealistic targets to achieve certain amount of bank deposits from clients, failing which they are sanctioned by delaying their promotion and in some cases result in job losses. In addition, some females encounter double jeopardy in employment and promotion into executive positions when they are married to men from other states as they are neither accepted in their husbands' states nor their own when competition for high positions are limited.

Other forms of glass ceiling effects include lack of mentors and opportunities to attend conferences, seminars or training due to arrangements or timing that are often unsuitable for married women. Similarly, female employees do not have easy access to informal network of communication as their male counterparts do. Male executives sometimes design requirements for high prestigious positions which females are unable to meet. In Nigeria, like most developing countries, men hold high ranking professional positions in organizations while females are over represented in lower paid jobs or professions such as nursing, teaching, social work, secretarial and catering jobs and even then, men still dominate at the top in these areas. All these glass ceiling effects reduce the chances of women rising to top decision making positions at their work places and affect the prospects of their engagement in top professional managerial and executive jobs. 


\section{Gender Discrimination Against Women in Appointive Positions and Education}

With regards to appointive positions in the public sectors in 2007, the percentage of women to men is $18 \%$ to $82 \%$ in the federal cabinet, Ambassadorial is $11.2 \%$ to $88.8 \%$, and Electoral Reform is $13.6 \%$ to $86.4 \%$. In the case of Education, Gender discrimination against women shows that while male adult literacy is $70.1 \%$, female adult literacy is $54.6 \%$ and the girl child continues to be deprived of her rights to quality education because priority is given to male education. The girl child ends up not been empowered and often exposed to harassments and intimidation. Inadequate educational preparation for the females results in their under employment or end up in informal sector with little or no opportunity for advancement. In the Federal Civil Service according to CEDAW, the women constitute $24 \%$ of the total number of persons employed in the Service. This inequality is even worse to a greater degree at the managerial position in which women constitute only $14 \%$. Gender stereotypes have also militated against women with $11 \%$ for women and $30 \%$ for men of those employed in industrial sectors. Women are seen mostly in the informal sector where they constitute $87 \%$. (CEDAW 2008)

When we consider that Nigeria population census of 2006 shows that the men were 71,709859 while women were $68,293,008$, it is obvious that the female are highly under represented in top executive and managerial positions in Nigeria public and private sector organizations. Lack of adequate education and their development therefore undermines their supply of needed human resources at such levels.

Well over the past thirty years, women have made significant improvement in all social indicators of development in Sub-Sahara Africa compared with statistics before the above indicated period. Women's participation in work in both public and private sectors has been increasing globally and this is equally true for Nigeria. There has been significant changes in the number of women entering into workforce and gender based division of labour. Employment profile has also changed with women now engaged and obtaining jobs in areas previously considered to be dominated by men. These changes not withstanding, there still remains a large gap in the gender ratio of males and females in executive and managerial positions, more so in healthcare service organizations the in Nigeria.

In 1985, Nigerian government ratified the Convention on the Elimination of all forms of Discriminations against Women. Following the famous world conference on women held in Beijing in the year 1995 the Federal government adopted the National gender policy on women in the 2000 which was a framework to monitor the implementation of the Beijing platform. The government went further to adopt National gender Policy in 2006 to replace the national policy on women in 2000 and yet regrettably the Government failed to implement the requirement in each of the cases. One of the strategies put in place to assist women to attain equal status with men in fields of economy is the Nigerian National Policy on Women, (NNPW, 2007), a framework designed to encourage women to attain top positions in any career and one of the cardinal objectives of the policy is to encourage equal access to education and skill acquisition for women in order to increase the demand for their labour at all levels but particularly at the managerial and executive levels. However, CEDAW 2008 observed that this policy has remained a paper-tiger as it is not backed up by force of law and yet to be Implemented. These factors have continued to widen the gap between women and men in Nigeria.

This paper argues that the continuous dominances of the male gender in management positions especially in health organizations in Nigeria is due to socially created inequality perpetuated by patriarchy, cultures and glass ceiling attitudes entrenched in the managerial structures and processes in both private and public organizations.

\section{Research Survey}

\section{An Empirical Survey Of Socio-Cultural Constraints On Work Performance And Advancement Of Female Executives In Public Health Institutions In Benin City, Edo State, Nigeria.}

\subsection{Purpose and Objectives of Survey}

In view of the foregoing, this study was undertaken with the contention that although there has been considerable development of women in various areas of endeavour in Nigeria over the past thirty years, there remains however, a large gap in the gender ratio of males and females sustained by negative socio-cultural factors which have the tendency of lowering female executive work performance and productivity. Health-Care sector where women are mostly engaged as Nurses and Matrons appears to suffer from gender discrimination in forms of socio-cultural barriers, particularly at the executive level. The research objectives therefore aim at determining:

a. The extent to which socio-cultural factors affect the performance of female executives in public healthcare organizations?

b. The extent to which there is a difference in the perception of the effects of socio-cultural factors on the performance of female executives across gender of respondents? 


\subsection{Research Settings}

The research survey was carried out among managers and executives in the University of Benin Teaching Hospital, University of Benin Health Center, Central Hospital, Benin City and among Senior Health and Health Related professional students on In-Service Education Programmes studying for the Diploma in Management and Administration and Masters Degree in Health Planning and Management in the Institute of Public Administration and Extension Services (IPAES), University of Benin.

\subsection{Research Population}

The research population thus consisted of Health and Health related professional employees of the above named institutions and the students on In-Service Education Programmes indicated above with the desire to be $95 \%$ confidence that the difference between the perception of the sample respondents and the true perception of the entire population about the subject matter of the research will differ by no more than $6 \%$ (0.06), $\mathrm{n}$ was obtained as:

$\mathrm{Za} / 2$ (Agbadudu, 2008)

$4 \mathrm{D}^{2}$

Where $a=$ level of significance $=5 \%$

Thus, $\mathrm{n}=\quad 1.96^{2}$

$\mathrm{D}=$ maximum difference allowable

$$
4 *(0.06)^{2}=266.78
$$

This was rounded up to 270 . Thus, a sample size of 270 was used. Proportional allocation was used to determine the number of respondents from each of the sampling units, owning to the non-uniformity in the population size from the respective units. Thereafter, simple random sampling (Lottery) method was used to select the desired sample size from each of the units. Thus, the sampling technique was simple random with lottery method serving as the basis of randomization. The data collection instruments were questionnaire, interview and secondary sources. The questionnaire was divided into two major parts. Part one featured items bothering on the bio-data of respondents while part two features items which sought to ascertain the perception of respondents on the subject matter of the research-"Socio-cultural factors as constraints to the performance of female executive in the public service". The question - response format to the items in the second part was of the Likert - type, with options ranging from a region of strong agreement (strongly agree) through a neutral zone (don't know) to a region of strong disagreement (strongly disagree). 270 questionnaires were administered out of which 185 representing 68.2 percent of them were retrieved. Research data were analyzed, using descriptive statistics such as frequency tables, percentages, mean, standard deviation, mean difference, and error mean, as well as inferential statistics such a the t-test for equality of means non-parametric tests-Mann-Whitney $U$. and Kolmogorv Smirnov Z.

\subsection{Table 1: Measurement of Variables}

\section{Presentation of Data and Research Findings}

Strongly Agree:

Agree :

Don't know:

Disagree:

Strongly Disagree:
2

1
0
-1
-2

Research Question One: To What Extent do you agree that Socio-Cultural Factors affect the Performance of Female Executives in Public Healthcare Organizations?

1.2 Table 2: Socio-Cultural Factors (Frequencies and Percentages)

1. To what extent do you agree that the following socio-cultural factors affect the performance of female executives in the public healthcare organizations?

\begin{tabular}{|c|c|c|c|c|c|c|c|c|c|c|c|c|c|}
\hline \multirow[t]{2}{*}{$\mathbf{S} / \mathbf{N}$} & & \multicolumn{2}{|c|}{$\begin{array}{l}\text { Strongly } \\
\text { Agree }\end{array}$} & \multicolumn{2}{|c|}{ Agree } & \multicolumn{2}{|c|}{ Disagree } & \multicolumn{2}{|c|}{$\begin{array}{l}\text { Strongly } \\
\text { Disagree }\end{array}$} & \multicolumn{2}{|c|}{$\begin{array}{l}\text { Don't } \\
\text { Know }\end{array}$} & \multicolumn{2}{|c|}{ Total } \\
\hline & & $\begin{array}{l}\mathbf{0} \\
\mathbf{O}\end{array}$ & $\%$ & $\begin{array}{l}\mathbf{N} \\
\mathbf{O}\end{array}$ & $\%$ & NO & $\%$ & NO & $\%$ & $\begin{array}{l}\mathbf{N} \\
\mathbf{O}\end{array}$ & $\%$ & NO & $\%$ \\
\hline a. & $\begin{array}{l}\text { Biological nature } \\
\text { of women }\end{array}$ & 39 & 21.08 & 73 & $\begin{array}{l}39.4 \\
6\end{array}$ & 49 & 26.49 & 16 & 8.65 & 8 & 4.32 & 185 & 100 \\
\hline b. & $\begin{array}{l}\text { Women's role in } \\
\text { children's up- } \\
\text { bringing. }\end{array}$ & 47 & 25.41 & 77 & $\begin{array}{l}41.6 \\
2\end{array}$ & 37 & 20.00 & 14 & 7.57 & 10 & 5.4 & 185 & 100 \\
\hline
\end{tabular}




\begin{tabular}{|l|l|l|l|l|l|l|l|l|l|l|l|l|l|}
\hline c. & $\begin{array}{l}\text { The popular } \\
\text { saying that } \\
\text { women should } \\
\text { only be seen and } \\
\text { not heard }\end{array}$ & 42 & 22.7 & 63 & 34.1 & 31 & 16.8 & 22 & 14.6 & 27 & 14.6 & 185 & 100 \\
\hline d. & $\begin{array}{l}\text { Women's feeling } \\
\text { of Inferiority } \\
\text { complex }\end{array}$ & 34 & 18.4 & 43 & $\begin{array}{l}23.2 \\
4\end{array}$ & 52 & 28.11 & 34 & 18.4 & 22 & 11.89 & 185 & 100 \\
\hline e. & $\begin{array}{l}\text { Women's belief } \\
\text { that strenuous } \\
\text { activities are for } \\
\text { men. }\end{array}$ & 44 & 23.78 & 45 & 24.3 & 44 & 23.78 & 36 & 19.46 & 16 & 8.65 & 185 & 100 \\
\hline f. & Religious beliefs. & 32 & 17.3 & 48 & 25.9 & 33 & 17.84 & 24 & 12.97 & 48 & 25.9 & 185 & 100 \\
\hline g. & $\begin{array}{l}\text { Extension of } \\
\text { cultural practices } \\
\text { to the work place }\end{array}$ & 36 & 11.35 & 84 & 45.4 & 56 & 30.27 & 7 & 3.78 & 17 & 9.18 & 185 & 100 \\
\hline h. & $\begin{array}{l}\text { Social norms and } \\
\text { folkways }\end{array}$ & 48 & 25.9 & 69 & 37.3 & 32 & 17.3 & 15 & 8.1 & 21 & 11.35 & 185 & 100 \\
\hline i. & $\begin{array}{l}\text { Popular views, } \\
\text { She is just a } \\
\text { woman }\end{array}$ & 17 & 9.19 & 76 & 41.0 & 58 & 31.35 & 16 & 8.65 & 17 & 4.86 & 185 & 100 \\
\hline j. & $\begin{array}{l}\text { Superstitions } \\
8\end{array}$ & 14 & 7.57 & 51 & 27.5 & 82 & 44.32 & 18 & 9.73 & 20 & 7.81 & 185 & 100 \\
\hline
\end{tabular}

\subsection{Table 3: Performance of Female Executives Vs. Socio-Cultural Factors (Scores)}

\begin{tabular}{|l|l|l|l|l|l|l|l|l|l|l|}
\hline Agree & 151 & 171 & 147 & 111 & 133 & 110 & 126 & 165 & 110 & 79 \\
\hline Disagree & 81 & 65 & 75 & 120 & 116 & 81 & 70 & 62 & 90 & 118 \\
\hline
\end{tabular}

\subsection{Results}

Table 4 Performance of female executives Versus Socio-Cultural factors

\begin{tabular}{|l|l|l|l|l|}
\hline & $\mathrm{N}$ & Mean & Std. Dev. & Std. error mean \\
\hline Agree & 10 & 130.300 & 28.71720 & 9.08118 \\
\hline Disagree & 10 & 87.800 & 22.37955 & 7.07704 \\
\hline
\end{tabular}

Independent Samples Test

Levene's Test for equality of Variances

$\mathrm{F}$

Sig.

.589 .453

t-test for Equality of Means

\begin{tabular}{|l|l|l|l|l|}
\hline & $\mathrm{T}$ & $\mathrm{df}$ & Sig. (2-tailed) & Mean Difference \\
\hline Equal Variances assumed & 3.691 & 18 & .002 & 42.5000 \\
\hline Equal Variances not assumed & 3.691 & 16.986 & .002 & 42.5000 \\
\hline
\end{tabular}

\begin{tabular}{|l|l|l|l|}
\hline \multicolumn{4}{|c|}{ 95\% confidence interval of the difference } \\
\hline & Std. error Difference & Lower & Upper \\
\hline Equal Variances assumed & 11.51313 & 18.31181 & 66.68819 \\
\hline Equal Variances not assumed & 11.51313 & 18.20791 & 66.79209 \\
\hline
\end{tabular}

Findings: Results in table 4 show that the Levene's test for equality of variances is not significant since the computed asymptotic significance probability associated with the F test value .589 for equality of Variances was found to be 0.453 . To this end, it is safe to assume equal variances at the ninety-five percent (95\%) confidence level. The mean difference between the scores of the respondents who agreed with the items suggesting that socio-cultural factors affect the performance of female executives and those of the respondents who disagreed was 42.500. A t-test for Equality of means (Equal Variances Assumed) showed that this difference was significant at the ninety- five percent (95\%) confidence level, given the calculated value of 3.691 and the associated asymptotic significant probability of 0.002 . The implication is that socio-cultural factors affect the performance of female executives. The result of the research findings lends credence to the theoretical proposition of the researcher which holds that there is a significant negative relationship between female executives performance in Nigerian healthcare services and socio-cultural factors. Given the foregoing, we can 
conclude at the $95 \%$ confidence level that the performance of female executives in the healthcare institutions surveyed is really affected by socio-cultural factors and practices.

\section{Discussions:}

With regard to factors militating against female executive performance, male respondent's listed cultural factors, illiteracy, child rearing practice, women's low esteem and low self-perception, male domineering tendencies which pervades all over Nigeria but the impact is acknowledged to be worse in the northern region of the country. Female respondents blame culture, male ego, religion, male restrictions common to marriages and poor self-perception. Although female respondents believe these problems to be widespread in Nigeria; they however, noted that they are more pronounced in the northern part of the country.

From the foregoing, one can say that all the socio-cultural factors taken together have influence on the performance of female executives in the public service. However, while some have much influence such as women's role in children's upbringing, which recorded 47 (25.41\%) for strongly agree and agree $77(41.62 \%)$, while extension of cultural practices to the workplace, shows for strongly agree $36(11.35 \%)$ and agree 84 $(45.41 \%)$ and the biological nature of women accounts for $39(21.08 \%)$ strongly agree and agree $73(39.46 \%)$. There are others which have moderate to little influence such as women's feeling of inferiority complex 34 (18.4\%) for strongly agree and 43 (23.34\%) for agree while women's belief that strenuous activities are for men, with strongly agree $44(23.78 \%)$ and agree 45 (24.32\%).

Research Question Two: To What Extent is there a Difference in the Perception of the effects of sociocultural factors on the performance of female Executives across Gender of respondents?

Table 5 Performance of Female Executives Vs Gender

\section{MALE}

FEMALE

\begin{tabular}{|l|l|l|l|l|l|l|l|l|l|l|l|l|l|}
\hline & SA & A & DK & D & SD & TOTAL & & SA & A & DK & D & SD & TOTAL \\
\hline a & 17 & 35 & 4 & 17 & 8 & 81 & A & 22 & 38 & 4 & 32 & 8 & 104 \\
\hline b & 20 & 38 & 5 & 13 & 5 & 81 & b & 27 & 38 & 5 & 24 & 9 & 104 \\
\hline C & 10 & 11 & 4 & 18 & 38 & 81 & C & 16 & 37 & 24 & 19 & 9 & 104 \\
\hline d & 18 & 21 & 7 & 21 & 14 & 81 & d. & 16 & 22 & 15 & 31 & 20 & 104 \\
\hline e & 24 & 21 & 8 & 20 & 8 & 81 & e. & 20 & 24 & 8 & 24 & 28 & 104 \\
\hline f & 15 & 22 & 22 & 15 & 7 & 81 & F & 17 & 26 & 26 & 18 & 17 & 104 \\
\hline g & 17 & 37 & 11 & 4 & 19 & 81 & G & 19 & 47 & 6 & 37 & 3 & 104 \\
\hline h & 23 & 36 & 4 & 12 & 6 & 81 & H & 25 & 33 & 17 & 20 & 9 & 104 \\
\hline i & 6 & 32 & 10 & 26 & 7 & 81 & I & 11 & 44 & 8 & 32 & 9 & 104 \\
\hline J & 5 & 21 & 5 & 39 & 11 & 81 & J & 9 & 40 & 15 & 43 & 7 & 104 \\
\hline
\end{tabular}

\section{ASSIGNMENT OF VALUES}

\begin{tabular}{|l|l|l|l|l|l|l|l|l|l|l|}
\hline Question & $\mathrm{a}$ & $\mathrm{B}$ & $\mathrm{C}$ & $\mathrm{D}$ & $\mathrm{e}$ & $\mathrm{F}$ & $\mathrm{G}$ & $\mathrm{h}$ & $\mathrm{I}$ & $\mathrm{J}$ \\
\hline MALE & 279 & 298 & 180 & 251 & 282 & 266 & 308 & 301 & 247 & 213 \\
\hline FEMALE & 328 & 359 & 347 & 295 & 290 & 320 & 354 & 332 & 328 & 343 \\
\hline
\end{tabular}

\section{Average Scores Using Number of Male Respondents $=81$ and Female $=104$}

\begin{tabular}{|l|l|l|l|l|l|l|l|l|l|l|}
\hline Question & $\mathrm{a}$ & $\mathrm{B}$ & $\mathrm{C}$ & $\mathrm{D}$ & $\mathrm{e}$ & $\mathrm{F}$ & $\mathrm{G}$ & $\mathrm{h}$ & $\mathrm{I}$ & $\mathrm{J}$ \\
\hline Male & 3.44 & 3.68 & 2.22 & 3.10 & 3.48 & 3.28 & 3.80 & 3.72 & 3.05 & 2.63 \\
\hline Female & 3.15 & 3.45 & 3.34 & 2.84 & 2.79 & 3.08 & 3.40 & 3.19 & 3.15 & 3.30 \\
\hline
\end{tabular}

\section{Results}

Table 6: Respondents Perception Versus Gender

\begin{tabular}{|l|l|l|l|l|}
\hline & $\mathrm{N}$ & Mean & Std. Dev & Std. error mean \\
\hline Male & 10 & 3.2400 & 0.50607 & 0.16003 \\
\hline Female & 10 & 3.1690 & 0.22103 & 0.06990 \\
\hline
\end{tabular}

Independent Samples Test

Levene's Test for Equality of Variances

$\mathrm{F}$

4.904
Sig

0.040 
t-test for Equality of Means

\begin{tabular}{|l|l|l|l|l|}
\hline & $\mathrm{T}$ & $\mathrm{df}$ & $\begin{array}{l}\text { Sig. (2- } \\
\text { tailed) }\end{array}$ & Mean Difference \\
\hline Equal Variances assumed & 0.407 & 18 & 0.689 & 0.071 \\
\hline Equal Variances not assumed & 0.407 & 12.313 & 0.691 & 0.071 \\
\hline
\end{tabular}

\begin{tabular}{|l|l|l|l|}
\hline \multicolumn{4}{|c|}{$95 \%$ confidence interval of the difference } \\
\hline & Std. error Difference & Lower & Upper \\
\hline Equal Variances assumed & 0.17463 & -0.29589 & 0.43789 \\
\hline Equal Variances not assumed & 0.17463 & -0.30842 & 0.45042 \\
\hline
\end{tabular}

Findings:

Findings reveal, in table 6 , that there is no significant difference in perception of roles across the gender of respondents. A comparison of respondents' of perception on the basis of gender revealed that the means of the mean scores obtained by male respondents was 3.2400 with a standard deviation of 0.50607 and a standard error mean of 0.16003 . The corresponding values for female respondents were 3.1690, 0.22103 and 0.06990 for mean of the mean scores, standard deviation, and standard error mean respectively, thus resulting in a mean difference of 0.071 . With a calculated $\mathrm{F}$ value of 4.904 and an associated significant probability of 0.040, the Levene's test for Equality of Variances was found to be significant at the five percent (5\%) level; thus implying that it is inappropriate to assume Equal Variance. A t-test for Equality of means, Equal Variances not assumed, showed that the resultant mean difference between the perception of male and female respondents was not significant at five percent (5\%) level since the computed significant probability of 0.689 is not less than 0.05 . Consequently, we may conclude at the ninety five percent $(95 \%)$ confidence level that there is no significant difference between the mean scores associated with the perception of male respondents and female respondents.

\section{Summary of Findings}

This study sets out to examine the extent to which socio-cultural factors such as biological nature of women, women's roles in children's upbringing, extension of cultural practices to workplace, social norms and folkways etc. militate against the performance of female executives in the public health organization in Benin City, Nigeria. The computed results in table 2, 3, and 4 show that the performance of female executives is significantly affected by socio-cultural factors indicated above with the mean value of those who "Agree" standing at 130.300 as against 87.800 for those who "Disagree". The t-test for equality of means and equal variances assumed also show that female executive performance is negatively affected by socio-cultural factors and table 4 further shows that this was significant at the $95 \%$ confidence level. The findings therefore confirm the research questions which sought to know whether female executive performance is negatively affected by socio-cultural factors in Nigeria.

The results in table 6 show that there is no significant difference in the perception of both males and females across gender in the public healthcare service. The mean value for males is 3.2400 while the mean value for females is 3.1690 and the standard error for male is 0.16003 and females 0.06990 . The t-test showed also that there was no difference in perception across genders with t-value of 0.407 for both equal variances assumed and equal variances not assumed. All these help us to conclude at the $95 \%$ level of confidence, that there is no significant difference in the perception of males and females across gender regarding the performance of female executives in the public healthcare service. The conclusion drawn from the analysis is that males and females uniformly agree to the fact that female executives' performance in the Public Healthcare Institutions surveyed is significantly affected by socio-cultural factors and there is no difference in perception across gender.

The respondents suggested a number of areas which should be given attention in order to improve the plight of female executives in workplace. These among others include appropriate legislations to counter negative cultural practices, encouragement of the females to be more focused, taking advantage of educational and training opportunities so as to be better equipped to compete effectively with their male counterparts, improving on perceptual competencies through education and enlightenment, pressing ahead persistently for equal advancement opportunities and so forth.

\section{Conclusion}

As stated earlier in this paper, although there has been general considerable improvement in the development of women well over 30 years, there is no doubt that there is still a large gap in the gender ratio of males and females sustained by socio-cultural stereotypes which continue to operate negatively against the performance of female executives in the public sector, especially in the healthcare organization. 
To achieve any concrete results on gender stereotypes, and gender equity issues, multi-sectoral approach which involves all stakeholders - Federal Government, Ministry of women Affairs and Social Development, men, women, boys, girls, infants, private sector organizations, experts on gender studies, researchers and implementers of research findings must be adopted. With the Ministry of Women Affairs and Social Development taking the leadership position, deliberate and systematic gender mainstreaming approach should be undertaken to ensure that the realities of live experiences, the needs of infants, children, men and women are built into the relevant legislations, strategies, policies and designs of appropriate plans, programmes, projects, budgeting, implementation, monitoring and evaluation geared toward reducing gender inequity. Political and financial commitments of the three tiers of governments, federal, state and local government and other appropriate institutions, including private sector must be sort, obtained and sustained. The Federal, State and Local Governments must stop paying lip services to eradicating harmful cultural practices. Global and National mandates on negative cultural practices must be honoured and implemented and private organizations must be integrated into the schemes of gender mainstreaming.

Above all, Governments at all levels should endeavour to provide adequate funding for gender research into all forms of discriminations as well as implementations of such findings. Implementation targets should be set, monitored and evaluated continuously and the Ministry of Women Affairs and Social Development should be given adequate support by the Government to achieve its mandate in its fight against gender stereotypes and gender inequity.

\section{References}

[1]. Afonja, S. (1996).Women and Political Agenda in Nigeria, paper presented at Fredrick Ebert Foundation Conference in popular participation in Governance, $16^{\text {th }}-18^{\text {th }}$ August, Ikogosi, Ekiti State, Nigeria.

[2]. Agbadudu, A.B. (2008). Statistics for Business and the Social Science, Uri Publishing Company, Benin City. Nigeria.

[3]. Alele-Williams, G. (1987). "Science, Technology and Mathematics (STM) Education for All, Including Women and Girls in Africa", a Keynote Address Delivered at the Commonwealth Regional Workshop on women and STM Education, Accra, Ghana.

[4]. BabaraEherenreich, "life without father", in McDowell and R. Pringle (1992), Defining women. London: Polity/Open University

[5]. Cockburn Cynthia (1993). Brothers: Male Dominance and Technological Change. London: Pluto. Retrieved from Wikipedia encyclopedia: http:/en.wikipedia.org/wiki/Patriarchy 2/21/2012

[6]. Davies-Netzley, Sally A. (1998).Women above the Glass Ceiling: Perceptions on Corporate Mobility and Strategies for Success Gender and Society, Vol.12, No.3, p.340,doi: 10.1177/0891243298012003006. Cited in Wikipedia, retrieved 2/27/2012.

[7]. Geert, Hofstede. (1994). Cultures and Organizations. London: Harper Collins. M. Tierney. 'Negotiating a software career

[8]. Heralambos, M. \&Holborn, M. (1995).Sociology Themes and Perspectives, $4^{\text {th }}$ Edition, Collins Educational, London.

[9]. Hesse-Bieber and Carter (2005). p. 77. http://en.wikipedia.org/wiki/GlassCeiling retrieved 2/27/2012

[10]. Jekayinfa, D.A. (1999). The Role of Nigerian Women in Culture and National Development, Journal of Educational Theory and Practice, Vol 5(1 \& 2).

[11]. Jones, W.O. (1969). Marketing of staple food crops in tropical African Food research institute California, Standard University Press.

[12]. "Meeting the Needs of the World's Women" (http://www.un.org/womenwatch/daw/daw/index.html)

[13]. National Gender Policy of the Federal Ministry of Women Affairs and Social Development, 2006.

[14]. Nevil, Ginny, Alice Pennicott, Joanna Williams, and Ann Worrall. Women in the Workforce: The Effect of Demographic Changes in the 1990s. London: The Industrial Society, 1990, p. 39, ISBN 978-0-85-290655-2. http://en/wikipedia.org/wiki/Glass ceiling retrieved 2/27/2012.

[15]. Nigeria $6^{\text {th }}$ Country Periodic Report on the Elimination of All Forms of Discrimination against Women (CEDAW, 2006)

[16]. Nigeria National Policy on Women (NNPW, 2007) "A frame designed to encourage women to attain top positions in any career".

[17]. Okome, MojubaolaOlunfunke. A snapped Democracy: T3 the Political Economy of The Structural Adjustment Program and the Political Transition in Nigeria, 1983-1993. MD: University Press of America, 1997.

[18]. Onvuejeogwu, M.A. (1994). Culture as a Vehicle for Nation Building. Paper Presented at a workshop organized by Edo State Council for Arts and Culture Benin City on $25^{\text {th }}$ February.

[19]. Onyinye Belinda Ndubuisi, (2007). PDF, The impact of Culture, Religion and Tradition on Women in Nigeria", wgc.womensglobalconnection.org/conf06proceedings/ retrieved 14/2/20

[20]. UNDP, (2009). "Social Indicators of Development in Nigeria": retrieved from www.UNDP.org on Nigeria 27/5/2010

[21]. U.S Department of Labor. "Good for Business: Making full use of the Nation's Human Capital" (http://www.dol.gov/oasam/program/history/reich/reports/ceiling.htm). Office of the Secretary.http://en.wikipedia.org/wiki/Glass ceiling retrieved 2/27/2012

[22]. Wikipedia, the free encyclopedia (2009), Glass Ceiling, retrieved from www.wikipedia.org on 27/5/2010 